\title{
THE DIFFERENTIAL EFFECTS OF A FOCUS ON SYMPTOMS VERSUS RECOVERY IN REDUCING STIGMA OF SCHIZOPHRENIA
}

Ross M.G. Norman ${ }^{1,3}$, Yixian $\mathrm{Li}^{2}$, Richard Sorrentino ${ }^{2}$, Elizabeth Hampson ${ }^{1,2}$, Yang $\mathrm{Ye}^{4}$ ${ }^{1}$ Departments of Psychiatry, ${ }^{2}$ Psychology and ${ }^{3}$ Epidemiology \& Biostatistics, Western University, London, Ontario Canada; ${ }^{4}$ Department of Experimental Clinical and Health Psychology, Ghent University, Belgium

Corresponding Author: $\quad$ Ross M.G. Norman, PhD CPsych

Professor, Departments of Psychiatry and

Epidemiology \& Biostatistics

Western University

A2-648, 800 Commissioners Road, East

London, Ontario Canada N6A 5W9

E-mail: rnorman@uwo.ca

PH: 519-685-8500 ext. 75493; FAX: 519-667-6657

Started: June 10, 2014

Draft Date: June 14, 2017

Format: $\quad$ Social Psychiatry and Psychiatric Epidemiology

Word Count: Abstract - 244 (150-250 words)

Body - $\quad 3,756$ (4500 words) 


\section{ABSTRACT}

Although it has been contended that contact with individuals with mental illness is the most effective intervention for stigma reduction, the content of the contact experience is likely to determine whether or not it is beneficial. In the current study, we extend investigations of the impact of whether such contact highlights the potential for recovery versus the nature of acute symptoms. We examine whether any differential impacts persist over a two week period and the extent to which they are mediated by perceptions of similarity and feelings of empathy and/or sympathy. We also measured an overt behaviour, seating distance, at two week follow-up. Using a randomized control design, we found that video exposure to an individual who described his recovery from schizophrenia was generally more effective in improving impressions and reducing preferred level of social distance than when the same person described acute symptoms of schizophrenia or a no-video control condition. These effects persisted up to two weeks. Although the symptom-focused video resulted in great sympathy for the person, this did not translate into positive impressions or reduced social distance. Mediational analyses yielded findings consistent with the benefits of the recovery video being partially mediated by increased perceptions of similarity to the person and lower feelings of sympathy. There were no differential effects of experimental condition on seating distance, but exposure to the recovery-focused video did result in less anxiety in anticipation of meeting the person in the video relative to the control condition.

Keywords: Contact; stigma; social distance; attitudes. 


\section{INTRODUCTION}

Despite initiatives to reduce the stigma of mental illness, there is little evidence for improvements in responses to those with mental illness, particularly schizophrenia[1-3]. An approach that is frequently endorsed for reducing mental illness stigma is contact with individuals with such disorders [4-6], and several interventions using direct or media-based exposure have yielded benefits $[7,8,4,9]$. Nevertheless, contact does not always lead to more positive responses [1012]. Noteworthy in this regard are reports that clinical exposure to individuals treated for mental illness does not reliably bring about positive responses and can have negative effects [13-16]. It is, therefore, important to clarify the circumstances under which exposure to an individual with mental illness is likely to yield beneficial effects $[17,18]$.

Impressions of people with schizophrenia may be heavily coloured by the acute symptoms that characterize the illness and associations with potential danger [19]. On the other hand, recovery, including remission of symptoms and resumption of good psychosocial functioning, is possible [20]. Penn, et al. [21] suggested that depictions of the acute symptoms may not reduce stigma and there is evidence that interventions simulating the acute symptoms of schizophrenia increase negative and discriminatory responses [22-24]. There is some evidence that portrayal of individuals who have been successfully treated for mental illness reduces stigma [25,26]. Li, et al. [27] recently compared the effect of a video in which an individual with a diagnosis of schizophrenia primarily described his acute symptoms to one in which he placed emphasis on recovery. An immediate post-test showed that the recovery video resulted in more positive 
impressions of and less social distance with respect to the person in the video, and less social distance to people in general with schizophrenia.

What are potential mechanisms by which contact might improve responses? Perceived similarity has long been recognized as a determinant of more positive responses to others [28], and there is evidence that increased perceptions of similarity can mediate the effects of positive intergroup contact [29,30]. Li, et al. [27] reported evidence consistent with perceived similarity mediating the effects of symptom versus recovery focused videos on attitudes and social distance. Research in other domains suggests that empathy and sympathy, can also influence likelihood of supportive or prosocial behaviour [31], and they have been postulated as contributors to responses to those with mental illness [32-35].

The current objectives were to replicate and extend the findings reported in Li, et al.[27]. Extensions include: presence of a control 'no video' group; a two week follow-up of outcomes; an examination of sympathy, empathy and perceived similarity with respect to the person in the video as possible mediators of any effects; and, at a two week follow-up, a behavioral measure related to physical distance [36]. The primary hypothesis was that a video highlighting recovery from schizophrenia would result in more positive outcomes in comparison to a symptom-focused video or a 'no video' control. The only exception to this directional hypothesis was with reference to sympathy, which could well be elicited more by the symptom-focused presentation [24].

As there has been little systematic investigation of the extent to which contact has parallel effects with respect to the contact person and people in general with a mental illness, we assessed both. 


\section{METHODS}

\section{Participants}

Participants were 218 individuals recruited for a study on "Understanding How Impressions are Formed" advertised at Western University, London Canada. Participants were compensated $\$ 25.00$ for participating in the study.Procedures were approved by the University's Research Ethics Board.

\section{Procedure}

The study consisted of two sessions scheduled approximately two weeks apart. The first session was completed on computers using MediaLab [37]. Participants were randomly assigned to one of three conditions: viewing a recovery-focused video, a symptom-focused video, or a 'no video' control condition. Each video was approximately 10 minutes in length and featured Andrew, a 30-year old who had been diagnosed with schizophrenia. The material in both videos accurately reflected Andrew's experiences. The first 3 minutes of each video were identical, consisting of Andrew introducing himself and talking about his early youth. After this, in the symptom-focused video, Andrew described acute phases of his illness, including experiences with hallucinations and paranoid delusions, and coming to terms with his illness and the need for treatment. At the end Andrew mentioned that he had now recovered and was receiving vocational training. In the recovery-focused video, Andrew only briefly mentioned his period of acute illness, but emphasized his recovery, including remission of symptoms, going back to school and work, as well as having a 
girlfriend. Control participants were shown a photo of Andrew and a brief description of him as a 30-year old community college student who had been diagnosed and treated for schizophrenia.

Participants completed measures that included overall impressions, perceived similarity, preferred social distance with respect to both Andrew and people in general treated for schizophrenia. The overall impression measure included five items reflecting traits implicated in the negative stereotype of people with schizophrenia $[19,38]$. The items included seven point ratings reflecting danger ("extremely dangerous" to "extremely safe"); difficulty of interaction ("extremely easy to interact with" versus "extremely difficult to interact with"); psychological weakness ("extremely fragile psychologically" versus "extremely strong"); incompetence ("extremely capable" versus "extremely incompetent") and prognosis ("extremely likely to again become ill with schizophrenia" versus "extremely unlikely to again become ill with schizophrenia").

Perceived similarity to the target was rated using the Inclusion of Others in Self Scale (IOS) [39]. Participants were shown seven diagrams consisting of two circles varying in the extent of overlap, and were asked to choose the diagram that best represented how much they shared characteristics with Andrew or people with schizophrenia in general. Scores range from 1 to 7 , where 1 indicates no perceived overlap and 7 indicates about $80 \%$ overlap. This was followed by an adapted measure of social distance [40,41], consisting of 11 items reflecting likelihood of engaging in a range of behaviours (e.g., speaking to the target on the street; going to a party at the target's house; renting a room to the target). 
The final measure was an 8-item scale developed to assess sympathy and empathy for Andrew. Although the terms empathy and sympathy are often conflated, it may be important to distinguish between them $[42,31,43]$. Empathy is generally defined as ability to comprehend another's emotional state, whereas sympathy reflects feelings of sorrow or concern for the other [31]. Consistent with this distinction, the empathy component consisted of ratings of the extent to which participants could: empathize with, identify with, imagine what it would be like to be in his position, and put themselves in his shoes. The sympathy items included: feeling sorry for, feeling bad for, feeling sad for, and being worried about Andrew. Factor analysis supported the discriminability of the domains and there was not a significant correlation between the resultant scales $(\mathrm{r}=.12 \mathrm{~ns})$.

All measures were scored so that higher values reflect more positive responses, i.e., less social distance; better impressions, greater similarity, sympathy and empathy. Finally, participants completed questions regarding their sex and age, as well as past experience with schizophrenia. The latter items were adapted from Angermeyer \& Matschinger [44].

A follow-up session was scheduled for two weeks later to assess persistence of effects. In addition to the measures included in the first sessions, we added a seating distance measure adapted from past research on stigma $[45,36]$. There is evidence that people maintain less physical distance from people they like, or with whom they feel comfortable [46]. In the first part of the session, participants again completed the measures described above. They were then told that the next stage involved meeting an individual who had been diagnosed with schizophrenia who would ostensibly further describe his experiences. In order to assess whether any impacts of the videos 
generalize beyond the person in it, for half the participants the person was described as a "young man" and the other half were told it would be Andrew, the person presented in the first session. Participants were taken to another room where there were seven chairs along a wall. They were told that the person they would be meeting had left the room but would return shortly. A book was on a chair at one end of the wall, with a jacket placed over the back of the chair, and the experimenter mentioned that the person had been sitting there. Participants were asked to take a seat and the experimenter unobtrusively noted the distance of the chosen seat from that designated as being occupied by the person with schizophrenia. Participants were then asked to complete the State Trait Anxiety Inventory-State Version (STAI), an instrument designed to assess situational anxiety. It consists of 20 items (e.g., I am tense; I am relaxed) on which the respondent is asked to indicate how they are feeling "right now". It was intended to measure anxiety in anticipation of meeting the person. Finally, they completed a questionnaire designed to assess suspiciousness regarding procedures, and were debriefed.

\section{Statistical Analysis:}

Analyses were completed using SPSS version 22. For outcomes assessed in both sessions, a repeated measure ANOVA was used with experimental condition and participant sex as betweensubject factors, and time as a within-subjects factor. Participant sex was included in order to assess whether there was any effect associated with this variable. Given a priori hypotheses that for all outcomes, except sympathy, the recovery video would yield more positive responses, planned comparisons were made between it and other conditions. Similar analyses (without the time factor) 
were completed for seating distance and anxiety in anticipation of meeting Andrew or a young man during the second session.

Mediational analyses to examine the role of perceived similarity, empathy and sympathy in determining impressions and social distance were carried out using the PROCESS module for SPSS [47].

\section{RESULTS}

Two hundred and eighteen individuals completed the first session; 56 males and 162 females. Their mean age was 22.1 years (range 18 to 61). The symptom video was viewed by 72 individuals, and 73 were in each of the recovery video and control conditions. One hundred and eighty completed the second session. There were no significant differences between those who did or did not attend the second session in sex, video condition or past experience with schizophrenia. Those who completed the second session were older (mean age 20.9 and 22.3 years, respectively; $\mathrm{t}=2.02 ; \mathrm{df}=216 ; \mathrm{p}<.05)$.

We will first describe the findings with respect to the dependent variables assessed at both sessions, including relevant mediational analyses. This will be followed by a description of findings with reference to seating distance and anxiety measured only during the second session. Outcomes at immediate and two week follow-up are presented in Table 1. The results of the repeated measures ANOVAS are presented in Table 2. For ease of presentation, only the significant main effects and interactions are reported.

\section{Overall Impressions:}


There were significant main effects of video condition and time on impressions of Andrew and people with schizophrenia in general. These reflect the positive effects of the recovery focused video in comparison to the other conditions and a general tendency for ratings to be less positive at two week follow-up. The significant video condition and time interaction on impression of Andrew reflect a change in the magnitude of the video effect over time but, nonetheless, individual comparisons revealed that the recovery video resulted in more positive impressions of each target at both times.

\section{Perceived Similarity:}

Video condition also had a significant effect on perceived similarity to Andrew, with comparisons showing the recovery-focused presentation led to greater perceived similarity than either of the other conditions at both post-tests.

With respect to perceived similarity to people with schizophrenia in general, the effect of video condition was qualified by a time $\mathrm{x}$ video $\mathrm{x}$ sex interaction. As Figure 1 illustrates, at immediate post-test the recovery video resulted in males perceiving greater similarity to those with schizophrenia than the symptom video; whereas at two weeks, males in both the control and recovery conditions perceived greater similarity than did those exposed to the symptom-focused video. For females, there were no significant differences in perceived similarity to the general target at either post-test as a function of experimental condition.

\section{Sympathy and empathy for Andrew:}


The symptom video elicited greater feelings of sympathy for Andrew than the other two conditions at both post-tests, although the video $\mathrm{x}$ time interaction reflects the differences being less pronounced at two weeks.

Both videos elicited greater empathy for Andrew at both post-tests than the control condition. The overall impact of video on empathy for Andrew is qualified by an interaction of sex with experimental condition, as illustrated in Figure 2. Comparisons showed that for males the recovery video led to greater empathy than either the symptom video or control condition, but for females both video conditions elicited greater empathy than the control condition. These patterns were similar at both post-tests. The significant main effect of time generally reflects less empathy at two weeks.

\section{Social Distance:}

Video condition also had a significant effect on social distance. Planned comparisons showed the recovery video resulting in less social distance towards Andrew than the other two conditions at both assessments. With reference to social distance to people with schizophrenia in general, only the recovery video led to less desire for social distance than the control condition at both post-tests, but there was not a significant difference on this measure between the recovery versus the symptom-focused video.

\section{Mediational Analyses}

There were two stages in the mediational analysis. The first was designed to replicate earlier findings [27], that perceived similarity mediates the effects of video condition on impressions and 
social distance. It was possible to do this with reference to both Andrew and with people with schizophrenia in general. Using PROCESS for SPSS [47], with recovery video as an indicator variable, we tested whether the data were consistent with perceived similarity mediating its beneficial effects on impressions and social distance. Statistical inferences were based on bootstrapping procedures with 10,000 iterations.

At both post-tests, there was evidence of the recovery video having both a direct effect $(\mathrm{B}=.33,95 \%, \mathrm{CI} .12-.54$, and $\mathrm{B}=.46,95 \%, \mathrm{CI} .26-.66$, respectively), and indirect effect through similarity ( $\mathrm{B}=.13,95 \%, \mathrm{CI} .04-.26$, and $\mathrm{B}=.18,95 \%$, CI.08-.31), in predicting impression of Andrew. Similarly, there were significant direct effects $(B=.33,95 \%, C I .12-.54 ; B=.34,95 \%, C I$.12-.55) and indirect effects $(\mathrm{B}=.19,95 \%, \mathrm{CI} .09-.33 ; \mathrm{B}=.11,95 \%, \mathrm{CI} .03-.23)$ on social distance to Andrew at both assessments.

There was no evidence of similarity mediating of the effect of the recovery video, on impression of and social distance towards people with schizophrenia in general.

For Andrew as a target, we were able to examine whether sympathy and/or empathy also mediated the impact of the recovery video. Using PROCESS procedure for multiple mediators (model 4), sympathy did emerge as an independent mediator, in addition to perceived similarity, in determining responses to Andrew, but empathy did not. There were significant indirect effects mediated by sympathy for impression of Andrew and time 1 and time 2 (B=.08, CI .02-.16; B=.06, CI $.01-.14)$ and for preferred social distance at both times $(B=.07, C I$.01-.15; $B=.08, C I$.02-.18). In each of these cases the mediation reflected the recovery video being associated with less sympathy and 
sympathy being associated with a less positive overall impression of Andrew and greater desire for social distance.

\section{Anxiety and seating distance}

Before analyzing the data concerning seating distance and anxiety while anticipating meeting an individual with schizophrenia, we examined responses to the questions assessing whether there were elements of the procedure that caused participants to be suspicious. A total of 27 individuals indicated suspiciousness about whether they really would be meeting someone with schizophrenia, and were omitted from the data analyses.

Table 3 summarizes the data by video condition and target. Analysis of variance yielded no significant effects on seating distance in anticipation of meeting Andrew or a young man. There was a borderline significant effect of video condition on anxiety in anticipation of meeting Andrew $(\mathrm{p}=10)$, with individual comparisons revealing less anxiety for those watching the recovery video than for those in the control condition $(\mathrm{p}=.04) .{ }^{1}$

\section{Effects of Experience}

No participant reported being personally diagnosed with schizophrenia. Following the methods of Angermeyer \& Matschinger [44], one quarter of respondents were classified as having had direct experience of schizophrenia as a result of a family member or acquaintance having been diagnosed, or having been involved in the treatment or cure of schizophrenia. Inclusion of direct

\footnotetext{
IIf these analyses are carried out using all participants, regardless of suspiciousness, the $\mathrm{p}$ value for the
} overall effect of video condition on anxiety is .07 , and for the individual comparison $p=.03$. 
experience as a covariate in the preceding analyses did not have a significant impact on any of the findings.

\section{DISCUSSION}

The current study replicates and extends findings of Li, et al. [27]. A recovery-focused video led to more positive impressions, greater perceived similarity, and less desire for social distance towards the person in the video immediately, and also after two weeks. The use of delayed assessments is important given that most research on stigma reduction strategies has not systematically assessed duration of effects [48].

While the recovery video resulted in more positive impressions of people in general with schizophrenia, effects on perceived similarity and social distance were less robust. For males, the symptom video resulted in less perceived similarity to people with schizophrenia, but there were no significant effects for females. Perhaps this reflects differential levels of identification with the person in the video as a function of being the same sex as the participant. The additional finding that the two videos resulted in differences in empathy for male but not female participants is consistent with this interpretation.

Only the recovery video resulted in less social distance to the more general target than the control condition, but there was not a significant difference between the two video conditions. Li, et al. (2017) also found that the effects of recovery versus symptom videos were not in parallel for responses to the individual and more general target, albeit with a different pattern than the current 
findings. Further research on the generalization of the effects of contact with an individual on responses to others with a mental illness, such as schizophrenia, is warranted.

Two previous studies have found evidence consistent with perceived similarity mediating the effects of interventions on stigmatizing responses [27,49]. The current findings provide further evidence for the likely importance of perceived similarity as a mechanism for stigma reduction, although the findings were specifically with respect to responses to the specific person portrayed in the video rather than the more general target of people with schizophrenia.

It has also been suggested that eliciting empathy and/or sympathy may reduce negative reactions to people with mental illness [32,50,34,35]. The symptom focused video increased sympathy for the ill person, while both videos increased empathy in comparison to the no video control. The increase in sympathy did not result in decreased preference for social distance. Furthermore, mediational analysis showed that the beneficial effects of the recovery video on impressions of, and social distance towards Andrew were partially mediated through reduced rather than increased sympathy. These findings suggest caution in using the elicitation of sympathy as an anti-stigma strategy [51].

One of the weaknesses of research on the stigma of mental illness is the paucity of measures related to overt behaviour [52]. Previous research demonstrated that attitudes towards individuals with schizophrenia can predict seating distance in a protocol similar to that used in the current study [36], although there is also evidence that such a relationship is less likely to be found for individuals with high levels of self-transcendent values [53]. We found no evidence for experimental condition having any impact on seating distance, but there was borderline evidence 
that the recovery video, relative to the control condition, reduced anxiety in anticipation of meeting Andrew. It could be speculated that, consistent with Norman, et al.[53], the failure to find an effect on seating distance may reflect the experimental procedures having increased the salience of values which over-rode any influence of attitudes on seating distance, but we have no data by which to assess this possibility. It might be that a behavioural measure occurring in closer proximity to the video presentation would have yielded predicted effects.

It is important to acknowledge the limitations of the current study. Although outcome assessments extended beyond the immediate responses characteristic of many studies, two weeks is not a long follow-up and we cannot be sure of effect duration beyond that point. In addition, while mediational analysis yielded findings consistent with similarity and sympathy being independent mechanisms responsible for the effects of our interventions, stronger evidence for their importance awaits further experimental investigation.

A further limitation is that only a male was presented in the video. For male participants only, the recovery video resulted in greater empathy for Andrew, whereas for females viewing either video brought about increased empathy. There was also evidence that for men the beneficial effects of the recovery-focused presentation were more likely to generalize to others with schizophrenia. As noted earlier, it is possible that these findings reflect differential dynamics, such as identification, when viewing someone of the same versus opposite sex. Clarification of these issues requires a study design using both sexes as the sources of contact. Finally participants in the current study were primarily university students. Although they represent an important target for 
anti-stigma intervention in their own right, it is important to asses generalizability of the findings to other populations.

As noted in our introduction, those who are developing programs for stigma reduction have relatively few empirically validated principles to rely on. One of the most frequently endorsed relates to the benefits of contact, but our findings temper this recommendation. Specifically, exposure to acute symptoms is less effective than contact highlighting potential for recovery. Focus on acute symptomatology is likely to make concerns about ease of interaction more salient than when recovery is highlighted and there is evidence that perceptions regarding costs and benefits of interaction are important determinants of social distance to those with mental illness [54]. Our findings are also consistent with reports that contact in clinical contexts, in which symptoms are prominent, does not reliably reduce stigma.

Program developers might also assume that stigma can be reduced by engaging public sympathy. Our findings indicate that although a focus on symptoms can result in greater sympathy or pity, a focus on recovery is more likely to result in improved attitudes and behavioural intentions. Eliciting sympathy will not necessarily reduce stigma. 
TABLE 1: Outcomes at Immediate and Two Week Post-test $(\mathrm{n}=180)$.

\begin{tabular}{|c|c|c|c|c|c|c|}
\hline \multirow{3}{*}{ Impression of Andrew } & \multicolumn{2}{|c|}{$\begin{array}{c}\text { Symptom Video } \\
(n=58)\end{array}$} & \multicolumn{2}{|c|}{$\begin{array}{c}\text { Recovery Video } \\
(n=58)\end{array}$} & \multicolumn{2}{|c|}{$\begin{array}{c}\text { Control } \\
(n=63)\end{array}$} \\
\hline & \multirow[t]{2}{*}{$\bar{x}$} & \multirow[t]{2}{*}{$(\mathrm{sd})$} & \multirow[t]{2}{*}{$\bar{x}$} & \multirow[t]{2}{*}{$(\mathrm{sd})$} & \multirow[t]{2}{*}{$\bar{x}$} & \multirow[t]{2}{*}{ (sd) } \\
\hline & & & & & & \\
\hline Immediate post-test & $4.1^{\mathrm{a}}$ & $(0.8)$ & $5.1^{\mathrm{b}}$ & $(0.7)$ & $4.4^{\mathrm{a}}$ & $(0.9)$ \\
\hline Two week post-test & $4.1^{\mathrm{a}}$ & $(0.6)$ & $4.6^{b}$ & $(0.8)$ & $3.9^{a}$ & $(0.7)$ \\
\hline \multicolumn{7}{|c|}{ Impressions of People with Schizophrenia } \\
\hline Immediate post-test & $3.7^{\mathrm{a}}$ & $(0.6)$ & $4.0^{\mathrm{b}}$ & $(0.8)$ & $3.5^{\mathrm{a}}$ & $(0.7)$ \\
\hline Two week post-test & $3.6^{\mathrm{a}}$ & $(0.6)$ & $3.9^{b}$ & $(0.7)$ & $3.5^{\mathrm{a}}$ & $(0.6)$ \\
\hline \multicolumn{7}{|l|}{ Similarity to Andrew } \\
\hline Immediate post-test & $2.1^{\mathrm{a}}$ & $(1.2)$ & $3.0^{\mathrm{b}}$ & $(1.5)$ & $2.1^{\mathrm{a}}$ & $(1.1)$ \\
\hline Two week post-test & $2.2^{\mathrm{a}}$ & $(1.0)$ & $2.7^{b}$ & $(1.3)$ & $2.2^{a}$ & $(1.0)$ \\
\hline \multicolumn{7}{|c|}{ Similarity to People with Schizophrenia } \\
\hline Immediate post-test & 2.0 & $(1.0)$ & 2.4 & $(1.4)$ & 2.2 & $(1.2)$ \\
\hline Two week post-test & 2.1 & (1.1) & 2.4 & (1.3) & 2.2 & $(1.2)$ \\
\hline \multicolumn{7}{|l|}{ Sympathy for Andrew } \\
\hline Immediate post-test & $3.4^{\mathrm{a}}$ & $(0.8)$ & $2.4^{\mathrm{b}}$ & $(0.6)$ & $2.8^{\mathrm{b}}$ & $(0.7)$ \\
\hline Two week post-test & $3.0^{\mathrm{a}}$ & $(0.8)$ & $2.4^{\mathrm{b}}$ & $(0.7)$ & $2.7^{b}$ & $(0.7)$ \\
\hline \multicolumn{7}{|l|}{ Empathy for Andrew } \\
\hline Immediate post-test & $2.8^{\mathrm{a}}$ & $(0.8)$ & $2.9^{a}$ & $(0.9)$ & $2.4^{\mathrm{b}}$ & $(0.7)$ \\
\hline Two week post-test & $2.7^{a}$ & $(0.9)$ & $2.7^{a}$ & $(0.8)$ & $2.4^{\mathrm{b}}$ & $(0.7)$ \\
\hline \multicolumn{7}{|c|}{ Social Distance to Andrew } \\
\hline Immediate post-test & $3.0^{\mathrm{a}}$ & $(1.0)$ & $3.5^{b}$ & $(0.8)$ & $2.8^{\mathrm{a}}$ & $(0.7)$ \\
\hline Two week post-test & $3.0^{a}$ & $(0.8)$ & $3.2^{b}$ & $(0.9)$ & $2.8^{\mathrm{a}}$ & $(0.7)$ \\
\hline \multicolumn{7}{|c|}{ Social Distance to People with Schizophrenia } \\
\hline Immediate post-test & 3.1 & $(0.9)$ & $3.2^{\mathrm{a}}$ & $(0.8)$ & $2.9^{b}$ & $(0.7)$ \\
\hline Two week post-test & 3.0 & $(0.8)$ & $3.2^{\mathrm{a}}$ & $(0.9)$ & $2.7^{b}$ & $(0.7)$ \\
\hline
\end{tabular}

Means with different superscripts $(a, b, c)$ were significantly different $(p<.05)$ in individual comparisons. 
TABLE 2: Significant effects from repeated measures analyses of variance.

\begin{tabular}{|c|c|c|c|c|}
\hline OUTCOME & EFFECT & $f$ & $d f$ & $p$ \\
\hline \multirow{3}{*}{ Impression of Andrew } & Time of post-test & 17.77 & 1,174 & $<.001$ \\
\hline & Video & 31.74 & 2,174 & $<.001$ \\
\hline & Time X Video & 9.48 & 2,168 & $<.001$ \\
\hline \multirow{2}{*}{$\begin{array}{l}\text { Impression of people with } \\
\text { schizophrenia }\end{array}$} & Time of post-test & 4.67 & 1,174 & .032 \\
\hline & Video & 7.51 & 1,174 & .001 \\
\hline Similarity to Andrew & Video & 7.37 & 2,168 & .001 \\
\hline \multirow{2}{*}{$\begin{array}{l}\text { Similarity to people with } \\
\text { schizophrenia }\end{array}$} & Video & 3.40 & 2,174 & .036 \\
\hline & Time X Video X Sex & 5.69 & 1,174 & .004 \\
\hline \multirow{3}{*}{ Sympathy for Andrew } & Time of post-test & 8.08 & 1,174 & .005 \\
\hline & Video & 11.13 & 1,174 & $<.001$ \\
\hline & Time X Video & 3.43 & 1,174 & .034 \\
\hline \multirow{3}{*}{ Empathy for Andrew } & Time of post-test & 8.04 & 1,174 & .005 \\
\hline & Video & 4.05 & 2,174 & .045 \\
\hline & Video X Sex & 3.93 & 2,174 & .049 \\
\hline Social distance to Andrew & Video & 8.87 & 2,174 & $<.001$ \\
\hline $\begin{array}{l}\text { Social distance to people } \\
\text { with schizophrenia }\end{array}$ & Video & 4.07 & 2,174 & .020 \\
\hline
\end{tabular}


TABLE 3: Seating Distance and Anxiety

\begin{tabular}{|c|c|c|c|c|c|c|}
\hline & \multicolumn{2}{|c|}{$\begin{array}{c}\text { Symptom Video } \\
(n=22)\end{array}$} & \multicolumn{2}{|c|}{$\begin{array}{c}\text { Recovery Video } \\
(n=30)\end{array}$} & \multicolumn{2}{|c|}{$\begin{array}{c}\text { Control } \\
(n=34)\end{array}$} \\
\hline & $\bar{x}$ & sd & $\overline{\boldsymbol{x}}$ & sd & $\bar{x}$ & sd \\
\hline \multicolumn{7}{|l|}{ Meeting Andrew } \\
\hline Seating Distance & 2.5 & 0.7 & 2.9 & 1.2 & 2.5 & 0.8 \\
\hline \multirow[t]{3}{*}{ Anxiety } & 36.82 & 9.3 & 35.2 & 10.2 & 41.7 & 12.4 \\
\hline & \multicolumn{2}{|c|}{$\begin{array}{c}\text { Symptom Video } \\
(n=38)\end{array}$} & \multicolumn{2}{|c|}{$\begin{array}{c}\text { Recovery Video } \\
(\mathrm{n}=28)\end{array}$} & \multicolumn{2}{|c|}{$\begin{array}{c}\text { Control } \\
(n=27)\end{array}$} \\
\hline & $\bar{x}$ & sd & $\bar{x}$ & sd & $\bar{x}$ & sd \\
\hline \multicolumn{7}{|l|}{ Meeting a Young Man } \\
\hline Seating Distance & 2.4 & 0.8 & 2.3 & 0.5 & 2.6 & 0.9 \\
\hline Anxiety & 37.3 & 9.0 & 33.8 & 9.5 & 38.4 & 9.2 \\
\hline
\end{tabular}


FIGURE 1: Interaction of time, video condition and participant sex in determining perceived similarity to people with schizophrenia.

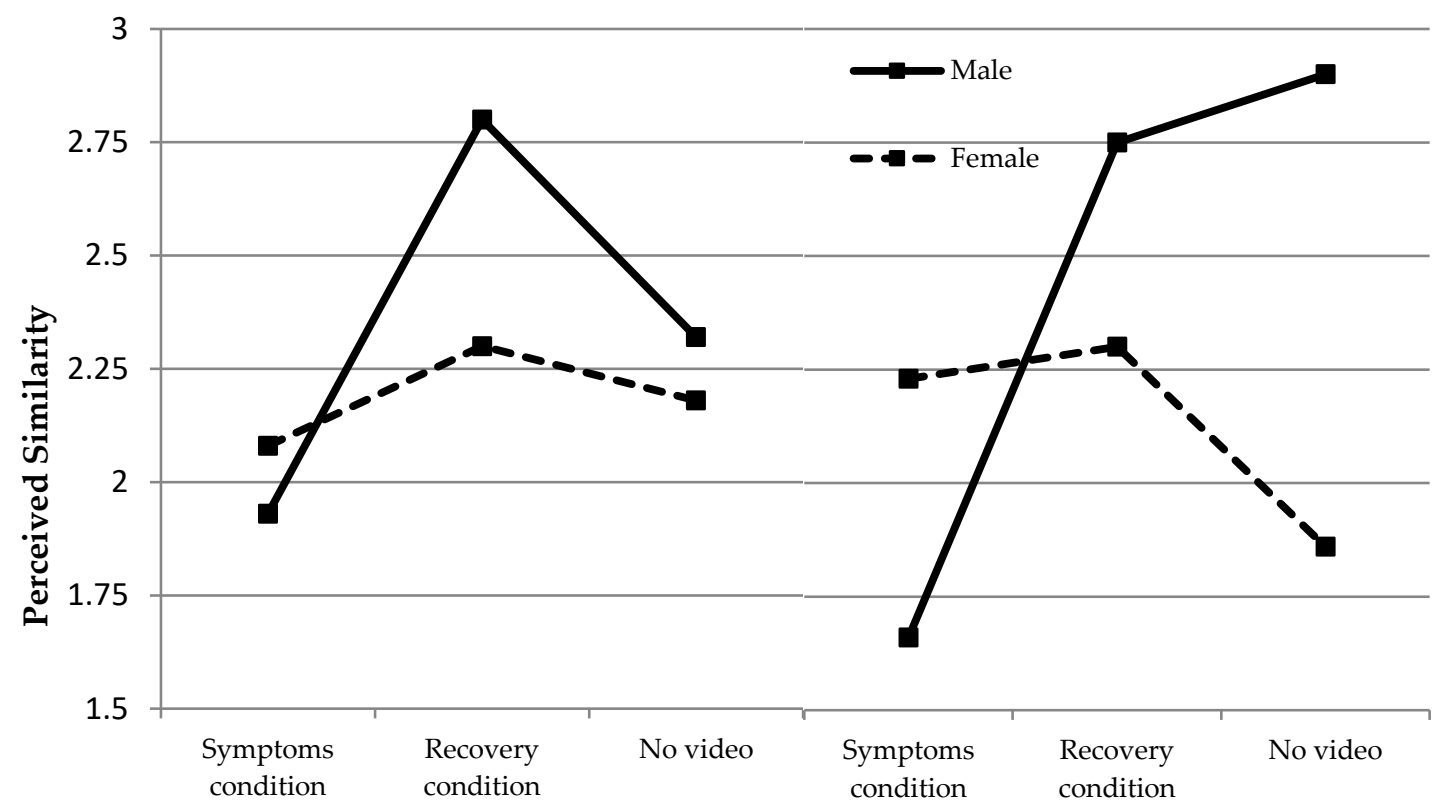

Immediate Post-test

Two Week Post-test 
FIGURE 2: Interaction of video condition and participant sex in determining empathy for Andrew.

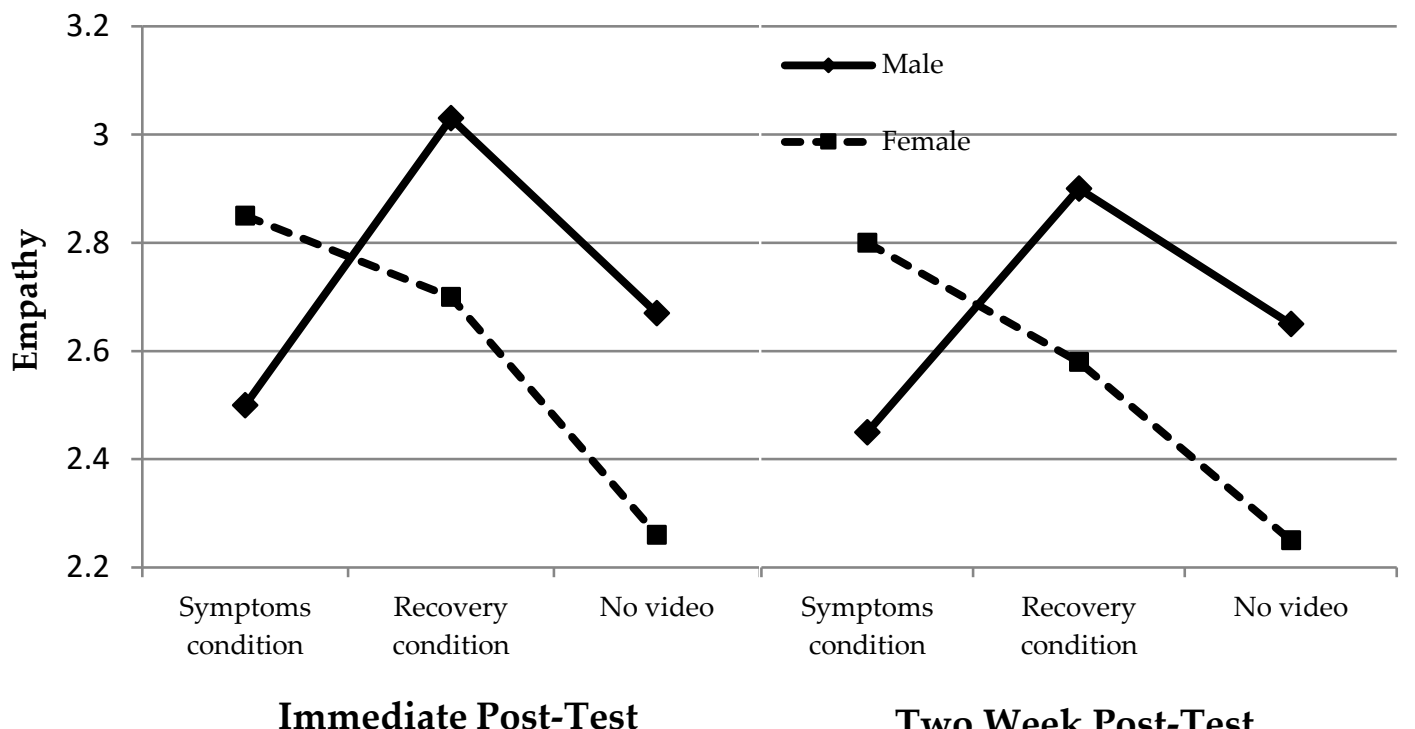




\section{AUTHOR DISCLOSURE:}

The authors have no conflicts of interest to declare.

\section{ACKNOWLEDGEMENTS:}

This work was supported by the Social Sciences and Humanities Research Council of Canada Grant 4310-2007-0342, Ross M. Norman, Principal Investigator. The authors thank Andrew for volunteering to be filmed in the videos. 


\section{REFERENCES}

1. Angermeyer MC, Matschinger H, Schomerus G (2013) Attitudes towards psychiatric treatment and people with mental illness: changes over two decades. Br J Psychiatry 203 (2):146-151. doi:10.1192/bjp.bp.112.122978bjp.bp.112.122978 [pii]

2. Pescosolido BA, Martin JK, Long JS, Medina TR, Phelan JC, Link BG (2010) "A disease like any other"? A decade of change in public reactions to schizophrenia, depression, and alcohol dependence. Am J Psychiatry 167 (11):1321-1330. doi:10.1176/appi.ajp.2010.09121743 appi.ajp.2010.09121743 [pii]

3. Schomerus G, Schwahn C, Holzinger A, Corrigan PW, Grabe HJ, Carta MG, Angermeyer MC (2012) Evolution of public attitudes about mental illness: a systematic review and meta-analysis. Acta Psychiatr Scand 125 (6):440-452. doi:10.1111/j.1600-0447.2012.01826.x

4. Corrigan PW, Morris SB, Michaels PJ, Rafacz JD, Rusch N (2012) Challenging the public stigma of mental illness: a meta-analysis of outcome studies. Psychiatr Serv 63 (10):963-973. doi:10.1176/appi.ps.2011005291372999 [pii]

5. Corrigan PW, Penn DL (1999) Lessons from social psychology on discrediting psychiatric stigma. Am Psychol 54 (9):765-776

6. Couture SM, Penn DL (2006) The effects of prospective naturalistic contact on the stigma of mental illness. J Comm Psychol 34 (5):635-645 
7. Clement S, van Nieuwenhuizen A, Kassam A, Flach C, Lazarus A, de Castro M, McCrone P, Norman I, Thornicroft G (2012) Filmed v. live social contact interventions to reduce stigma: randomised controlled trial. Br J Psychiatry 201 (1):57-64. doi:10.1192/bjp.bp.111.093120 bjp.bp.111.093120 [pii]

8. Janouskova M, Tuskova E, Weissova A, Trancik P, Pasz J, Evans-Lacko S, Winkler P (2016) Can video interventions be used to effectively destigmatize mental illness among young people? A systematic review. Eur Psychiatry 41:1-9. doi:S0924-9338(16)30154-7 [pii] 10.1016/j.eurpsy.2016.09.008

9. Pinfold V, Toulmin H, Thornicroft G, Huxley P, Farmer P, Graham T (2003) Reducing psychiatric stigma and discrimination: evaluation of educational interventions in UK secondary schools. Br J Psychiatry 182:342-346

10. Pattyn E, Verhaeghe M, Bracke P (2013) Attitudes toward community mental health care: the contact paradox revisited. Community Ment Health J 49 (3):292-302. doi:10.1007/s10597-0129564-4

11. Griffiths KM, Carron-Arthur B, Parsons A, Reid R (2014) Effectiveness of programs for reducing the stigma associated with mental disorders. A meta-analysis of randomized controlled trials. World Psychiatry 13 (2):161-175. doi:10.1002/wps.20129

12. Mehta N, Clement S, Marcus E, Stona AC, Bezborodovs N, Evans-Lacko S, Palacios J, Docherty M, Barley E, Rose D, Koschorke M, Shidhaye R, Henderson C, Thornicroft G (2015) Evidence for effective interventions to reduce mental health-related stigma and discrimination in the 
medium and long term: systematic review. Br J Psychiatry 207 (5):377-384.

doi:10.1192/bjp.bp.114.151944207/5/377 [pii]

13. Arkar H, Eker D (1997) Influence of a 3-week psychiatric training programme on attitudes toward mental illness in medical students. Soc Psychiatry Psychiatr Epidemiol 32 (3):171-176

14. Economou M, Peppou LE, Louki E, Stefanis CN (2012) Medical students' beliefs and attitudes towards schizophrenia before and after undergraduate psychiatric training in Greece. Psychiatry Clin Neurosci 66 (1):17-25. doi:10.1111/j.1440-1819.2011.02282.x

15. Omori A, Tateno A, Ideno T, Takahashi H, Kawashima Y, Takemura K, Okubo Y (2012) Influence of contact with schizophrenia on implicit attitudes towards schizophrenia patients held by clinical residents. BMC psychiatry 12:205. doi:10.1186/1471-244X-12-2051471-244X-12205 [pii]

16. Pillai SK, Jesjeet SG, Jamburiathan ST (2006) Psychiatric posting in final year medical students. Do attitudes change? Malaysian J Psychiatry 15:26-34

17. Greenblatt AM, Pinto MD, Higgins MK, Berg CJ (2016) Exploring the Relationships Among Level of Contact, Nature of Contact, and Mental Illness Stigma in Adolescent Girls. Issues Ment Health Nurs 37 (1):10-18. doi:10.3109/01612840.2015.1087604

18. Moxam L, Taylor EN, patterson D, Brighton R, Sumskis S, Keough E, Heffernan T (2016) Can a clinical placement influence stigma? An analysis of social distance. Nursing Education Today 44:170-174 
19. Angermeyer MC, Matschinger H (2004) The stereotype of schizophrenia and its impact on discrimination against people with schizophrenia: Results from a representative survey in Germany. Schizophr Bull 30 (4):1049-1061

20. Jăăskeläinen E, Juola P, Hirvonen N, McGrath JJ, Saha S, Isohanni M, Veijola J, Miettunen J (2013) A systematic review and meta-analysis of recovery in schizophrenia. Schizophr Bull 39 (6):1296-1306. doi:10.1093/schbul/sbs130sbs130 [pii]

21. Penn DL, Guynan K, Daily T, Spaulding WD, Garbin CP, Sullivan M (1994) Dispelling the stigma of schizophrenia: What sort of information is best? Schizophr Bull 20 (3):567-578

22. Brown SA (2010) Implementing a brief hallucination simulation as a mental illness stigma reduction strategy. Community Ment Health J 46 (5):500-504. doi:10.1007/s10597-009-9229-0

23. Brown SA, Evans Y, Espenschade K, O'Connor M (2010) An examination of two brief stigma reduction strategies: filmed personal contact and hallucination simulations. Community Ment Health J 46 (5):494-499. doi:10.1007/s10597-010-9309-1

24. Ando S, Clement S, Barley EA, Thornicroft G (2011) The simulation of hallucinations to reduce the stigma of schizophrenia: a systematic review. Schizophr Res 133 (1-3):8-16. doi:10.1016/j.schres.2011.09.011S0920-9964(11)00490-7 [pii]

25. McGinty EE, Goldman HH, Pescosolido B, Barry CL (2015) Portraying mental illness and drug addiction as treatable health conditions: effects of a randomized experiment on stigma and 
discrimination. Social science \& medicine (1982) 126:73-85.

doi:10.1016/j.socscimed.2014.12.010S0277-9536(14)00799-0 [pii]

26. Reinke RR, Corrigan PW, Leonhard C, Lundin RK, Kubiak MA (2004) Examining two aspects of contact on the stigma of mental illness. J Soc Clin Psychol 23 (3):377-389

27. Li Y, Sorrentino P, Norman R, Hampson E, Ye Y (2017) Effects of informational video, similarity and uncertainty orientation on reducing the stigmatization of schizophrenia. Pers Indiv Diff 106 $(117-121)$

28. Byrne D (1971) The Attraction Paradigm. Academic Press, New York

29. McGlothin H, Killen M (2005) Children's perceptions of intergroup and intragroup similarity and the role of social experience. Appl Develop Psychol 26:680-698

30. Stathi S, Crisp RT (2010) Intergroup contact and the projection of positivity. Int J Intercult Rel 34:580-591

31. Eisenberg N (2000) Emotion, regulation, and moral development. Annu Rev Psychol 51:665-697. doi:10.1146/annurev.psych.51.1.665

32. Bunn W, Terpstra J (2009) Cultivating empathy for the mentally ill using simulated auditory hallucinations. Acad Psychiatry 33 (6):457-460. doi:10.1176/appi.ap.33.6.45733/6/457 [pii]

33. Corrigan PW (2000) Mental health stigma as social attribution: Implications for research methods and attitude change. Clin Psychol: Sci Pract 7 (1):48-67 
34. Obonsawin MC, Lindsay A, Hunter SC (2013) Beliefs and emotions have different roles in generating attitudes toward providing personal help and state-sponsored help for people with a mental illness. Compr Psychiatry 54 (5):581-588. doi:10.1016/j.comppsych.2012.11.004 S0010$440 \times(12) 00253-2$ [pii]

35. Ungar T, Knaak S, Szeto AC (2016) Theoretical and Practical Considerations for Combating Mental Illness Stigma in Health Care. Community mental health journal 52 (3):262-271. doi:10.1007/s10597-015-9910-4 10.1007/s10597-015-9910-4 [pii]

36. Norman RM, Gawronski B, Hampson E, Sorrentino RM, Szeto A, Ye Y (2010) Physical proximity in anticipation of meeting someone with schizophrenia: the role of explicit evaluations, implicit evaluations and cortisol levels. Schizophr Res 124 (1-3):74-80. doi:10.1016/j.schres.2010.07.021 S0920-9964(10)01437-4 [pii]

37. Jarvis BG (ed) (2004) Medialab Version 3.24. Empirisoft Corporation, New York, NY

38. Hayward P, Bright JA (1997) Stigma and mental illness: A review and critique. J Ment Health 6 (4):345-354

39. Aron A, Aron EN, Smollan D (1992) Inclusion of the Other in Self Scale and the structure ofinterpersonal closeness. J Pers Soc Psychol 63 (4):596-612

40. Bogardus ES (1925) Social distance and its origins. JApplied Soc 9:216-226

41. Link BG, Yang LH, Phelan JC, Collins PY (2004) Measuring mental illness stigma. Schizophr Bull 30 (3):511-541 
42. Clark AJ (2010) Empathy and sympathy: Therapeutic distinctions in counseling. J Ment Health Couns 32 (2):95-101

43. Vossen HGM, Piotrowski JT, Valkenburg PM (2015) Development of the Adolescent Measure of Empathy and Sympathy. Pers Indiv Diff 74:66-71

44. Angermeyer MC, Matschinger H (1996) The effect of personal experience with mental illness on the attitude towards individuals suffering from mental disorders. Soc Psychiatry Psychiatr Epidemiol 31 (6):321-326

45. Barrios BA, Corbitt LC, Estes JP, Topping JS (1976) Effect of a social stigma on interpersonal distance. Psychol Rec 26 (3):343-348

46. Gifford R, O'Connor B (1986) Nonverbal intimacy: Clarifying the role of seating distance and orientation. J Nonverbal Behav 10 (4):207-214

47. Hayes AF (2013) Introduction to Mediation, Moderation and Conditional Process Analysis: A Regression-based Approach. Guilford Press, Chicago

48. Corrigan P, Michaels PJ, Morris S (2015) Do the effects of antistigma programs persist over time? Findings from a meta-analysis. Psychiatr Serv 66 (5):543-546. doi:10.1176/appi.ps.201400291

49. Schomerus G, Angermeyer MC, Baumeister SE, Stolzenburg S, Link BG, Phelan JC (2016) An online intervention using information on the mental health-mental illness continuum to reduce stigma. Eur Psychiatry 32:21-27. doi:10.1016/j.eurpsy.2015.11.006S0924-9338(15)00683-5 [pii] 
50. Corrigan PW, Lickey SE, Campion J, Rashid F (2000) Mental health team leadership and consumers satisfaction and quality of life. Psychiatric services (Washington, DC 51 (6):781-785

51. Corrigan PW (2016) Lessons learned from unintended consequences about erasing the stigma of mental illness. World Psychiatry 15 (1):67-73. doi:10.1002/wps.20295

52. Hinshaw SP (2007) The Mark of Shame: Stigma of Mental Illness and an Agenda for Change. Oxford University Press, New York, NY

53. Norman RM, Sorrentino RM, Gawronski B, Szeto AC, Ye Y, Windell D (2010) Attitudes and physical distance to an individual with schizophrenia: the moderating effect of selftranscendent values. Soc Psychiatry Psychiatr Epidemiol 45 (7):751-758

54. Norman RM, Windell D, Manchanda R (2012) Examining differences in the stigma of depression and schizophrenia. Int J Soc Psychiatry 58 (1):69-78. doi:0020764010387062 [pii]10.1177/0020764010387062 